\title{
Predictability of CAD/CAM fabricated aluminum oxide core crowns and veneers
}

\author{
${ }^{1}$ MUDr. Radek Mounajjed, DDS, PHD; ${ }^{2}$ Basel Azar DDS, MSc; ${ }^{3}$ Doc. Miloš \\ Špidlen MD, PHD'; ${ }^{4}$ Prof. Steven.E.Eckert, DDS, MS \\ Department of prosthetic dentistry, Palacky university-Czech republic \\ DCM, Private dental clinic, Hradec Králové, Czech Republic \\ Department of prosthetic dentistry, Palacky university-Czech republic \\ Associate professor, faculty of medicine and dentistry, Palacky university-Czech republic \\ Professor Emeritus, Mayo Clinic, college of Medicine, Rochester, MN, USA
}

\begin{abstract}
Statement of problem. The application of new materials and techniques creates a tremendous need for appropriate clinical guidelines. There is a lack of evidence based clinical study concerning the use of $C A D / C A M$ fabricated aluminum oxide core crowns and veneers.

Purpose. The purpose of the study was to evaluate the clinical performance and predictability of CAD/CAM fabricated aluminum oxide core crowns and veneers after an observation period of one to four years.

Material and methods. The study was performed as a retrospective clinical evaluation of all consecutively treated patients treated from January 1, 2004 through June 30, 2007 who provided consent to be included in this assessment. Complications of the crowns and veneers were divided the into four categories: Minor complications $(M C)$, Loosening $(L)$, Veneer fracture $(V F)$ and Failure $(F)$. Survival rate of the restorations were estimated by using Kaplan-Meier statistical analysis.

Results. A total of 603 alumina core crowns were placed in 350 patients while 166 alumina core veneers were placed in 53 patients. All restorations were fabricated for premolar, canine or incisor teeth; none of the crowns were used on molar teeth. For the crowns the 4-year cumulative failure rate was $2.79 \%$. By contrast the alumina veneer core veneers demonstrated cumulative failure at 4 years of $23.05 \%$.

Conclusion. Based upon this retrospective study of 603 Ceramic crowns and 166 ceramic veneers with a minimum of 12 months and a maximum of 48 months both of which used a high-strength alumina core it appears that the clinical performance of the ceramic crowns (97.1\% survival probability) at up to 4 years is far superior to that of the ceramic veneer (63.6\% survival probability).
\end{abstract}

\section{Introduction}

Metal ceramic crowns, although predictable relative to clinical performance(1) are thought to be technically difficult/unforgiving when truly aesthetic restorations are necessary(2,3). One approach that has been suggested to address the complexity of use of metal ceramic crowns is to utilize crowns that have no metal substructure and instead use a metallic oxide, ceramic core with a veneer of aesthetic porcelain. The so-called ceramic crown was thereby created (4-6).

During this same time period there was recognition that ceramic crowns required the reduction of much tooth structure to allow sufficient bulk of ceramic material to provide strength and sufficient aesthetics to the crown(7). This led to the advent of bonded porcelain laminate veneers as these restorations utilized no traditional metal substructure, created less metameric effects and gained strength from the underlying bond to enamel.(8)Porcelain laminate veneers were initially introduced using feldspathic porcelain, a material that exhibits only moderate material strength. The inherent weakness of this material was thought to be responsible for the complication of porcelain chipping or, more importantly, fracture of the entire restoration.(9)

Other ceramic materials, namely materials that are fabricated from leucite reinforced ceramic, aluminum oxide, lithium disilicate or zirconia, exhibit more favorable material strength properties(10-13). Although these materials generally require a veneering porcelain, manufacturers have suggested that the inherent strength of the core material may be sufficient to compensate for the weakness of the veneer. Consequently these materials have been promoted for use as the core material for porcelain laminate veneers and for ceramic crowns(14-16). Aluminum oxide core ceramic crown appeared to function well regardless of the specific technique that was used to cement or lute the restorations(17-21).

When using the materials, the clinician is cautioned to carefully follow the guidelines provided by the material manufacturers. It is thought that careful attention to detail will lead to clinical success. Furthermore, the application of new materials and techniques creates a tremendous need for appropriate clinical guidelines(2224). The purpose of this study was to evaluate the clinical performance of CAD/CAM generated aluminum oxide core crowns and veneers over a time frame of up to four years. 


\section{Material And Methods}

The study was performed as a retrospective clinical evaluation of all consecutively treated patients treated from January 1, 2004 through June 30, 2007 who provided consent to be included in this assessment. Data analysis was performed after June 30, 2008 to ensure that all included restorations were in function for a minimum of 12 months. Alumina core crowns (Nobel Biocare AB, Göteborg, Sweden) or aluminous oxide core veneers (Nobel Biocare AB, Göteborg, Sweden) were used in all patients.

The restorations were fabricated according to manufacturer recommendations. The core materials for the full crowns were either 0.4 or $0.6 \mathrm{~mm}$. Ceramic crowns were luted using glass ionomer, resin reinforced glass ionomer RelyX Luting Plus Cement (3M ESPE) or resin self-adhesive luting agents RelyXUnicem (3M ESPE). The veneers all utilized a $0.25 \mathrm{~mm}$ core and all veneers were bonded using light cured bonding materials Adper Single Bond 2 (3M ESPE) and self-adhesive luting agents RelyXUnicem (3M ESPE). Restorations were placed on premolar, cuspid and incisor teeth; no restorations were placed on molars. All restorations were evaluated annually to determine the presence or absence of any complications. Complications of the crowns and veneers were divided into four categories:

Minor complications (MC): chipping of the restoration that resulted in a need for smoothing and polishing but not replacement of the restoration. Loosening (L): Failure of the bond with no damage to the restoration. The restoration can thereby be replaced without re-fabrication. Veneer fracture (VF): Veneer Fracture with the possibility of re- cementation of the fragments

Failure (F): Complete failure of the restoration requiring re-fabrication.

Scanning electron microscopy was utilized to assess the micro-roughness of the intaglio surface of a representative veneer. This was compared with feldspathic veneer restorations at the same magnification (500X)

Survival rate of the restorations were estimated by using Kaplan-Meier statistical analysis. This statistical methodology allowed time-dependent assessment of the clinical performance of the two types of restorations.

\section{Results}

A total of 603 alumina core crowns were placed in 350 patients while 166 alumina core veneers were placed in 53 patients. All restorations were fabricated for premolar, cuspid or incisor teeth; none of the crowns were used on molar teeth.

For the ceramic crowns the four-year cumulative failure rate was $2.79 \%$ while the number of crowns that loosened at four years was $1.91 \%$ and the number of crowns experiencing minor complications was $8.69 \%$. There were no bilayered alumina crowns that exhibited veneer fracture that could be managed with recementation of the veneers. (Tables I-III) Kaplan-Meier survival analysis demonstrated a $97.1 \%$ probability of ceramic crown survival to year 4 (Figure 1).

By contrast the alumina veneer core veneers demonstrated cumulative failure at four years of $23.05 \%$. The complications that required clinical intervention: veneer fracture, veneer dislodgment and minor chipping occurred at cumulative rates of $7.92 \%, 5.83 \%$ and $3.20 \%$ respectively. (Table IV-VII) The Kaplan-Meier survival analysis demonstrated a $64 \%$ probability that the aluminum oxide veneer would survive to year 4(Figure 1).

Scanning electron microscopic images of the alumina veneers demonstrated less microroughening than that seen with feldspathic veneers. This was a visual assessment only but was made at the same magnification (X500) for both materials.(Figure 2,3)

\section{Discussion}

The alumina core restoration allows clinicians to fabricate ceramic restorations which are often described as providing clinical benefits relative to the fabrication of aesthetic restorations. Although restorations may provide esthetic benefits these benefits are of little value if the restorations themselves are not reliable.

In this retrospective study a relatively high probability of survival to four years of function was demonstrated with alumina core ceramic crown restorations. These restorations appeared to function well regardless of the specific technique that was used to cement or lute the restorations(20,21,22). These results were in distinct contrast to the large number of absolute failures that were observed with the alumina core ceramic veneers even though the veneers were bonded using recommendations provided by the manufacturer.

Traditional techniques utilized to secure porcelain veneers to the underlying tooth structure utilizing bonding technology whereby micromechanical etching of the enamel is performed and then composite bonding is utilized to secure the etched and silanated veneer to the enamel $(23,24)$. Assessment of the surface of the alumina core at high magnification (X500) (figure 4) fails to demonstrate roughness that is similar to that seen with etched feldspathic porcelain. It may be postulated that the relative lack of micro-roughing up the aluminum oxide core may be responsible, in part, for the high failure rate experienced in this study. 
Minor chipping of the ceramic crowns occurred at a higher rate than that observed with the ceramic veneers. In contrast the rate of restoration dislodgment was appreciably higher for the veneers than it was for crowns. Considering all this information it may be possible to suggest that the relative security of the ceramic crown may result in higher force application to the crowns which then leads to minor damage to the ceramic material in clinical function.

\section{Conclusion}

Based upon this retrospective study of 603 ceramic crowns and 166 ceramic veneers with a minimum of 12 months and a maximum of 48 months both of which utilized a high-strength alumina core, it appears that the clinical performance of the ceramic crowns (97.1\% survival probability) at up to four years is far superior to that of the ceramic veneer (63.6\% survival probability).

[1]. Heintze SD, RoussonV. Survival of zirconia- and metal-supported fixed dental prostheses: a systematic review. Int J Prosthodont. 2010; 23: 493-502

[2]. Salinas TJ, Koka S. Porcelain-fused-to-metal technology--still the standard of care for single-tooth crowns?. Compend Contin Educ Dent. 2007;28:334-9.

[3]. Rasetto FH, Driscoll CF, Prestipino V, Masri R, Fraunhofer JA. Light transmission through all-ceramic dental materials: a pilot study. J Prosthet Dent. 2004;91:441-6.

[4]. Zitzmann NU, Galindo ML, Hagmann E, Marinello CP. Clinical evaluation of Procera AllCeram crowns in the anterior and posterior regions. Int J Prosthodont. 2007;20:239-41

[5]. 5.Vailati F, Belser UC. Full-mouth adhesive rehabilitation of a severely eroded dentition: the three-step technique. Part 3. Eur J Esthet Dent 2009;3:236-57

[6]. Sorrentino et al. Clinical Evaluation of 209 All-Ceramic Single Crowns Cemented on Natural and Implant-Supported Abutments with Different Luting Agents: A 6-Year Retrospective Study. Clinical implant dentistry and related research (2009) [Epub ahead of print]

[7]. Shirakura A, Lee H, Geminiani A, Ercoli C, Feng C. The influence of veneering porcelain thickness of all-ceramic and metal ceramic crowns on failure resistance after cyclic loading. J Prosthet Dent 2009;101:119-27

[8]. Aykor A, Ozel E. Five-year clinical evaluation of 300 teeth restored with porcelain laminate veneers using total-etch and a modified self-etch adhesive system. Oper Dent 2009;34: 516-23

[9]. Cehreli MC, Kokat AM, Ozpay C, Karasoy D, Akca K. A Randomized Controlled Clinical Trial of Feldspathic Versus GlassInfiltrated Alumina All-Ceramic Crowns: A 3-Year Follow-up. Int J Prosthodont 2011;24:77-84

[10]. Dündar M, Artunc C, Toksavul S, Ozmen D, Turgan N. Determination of elemental composition of substance lost following wear of all-ceramic materials. Int J Prosthodont 2003;16:261-4

[11]. Bindl A, Luthy H, Mörmann HW. Strength and fracture pattern of monolithic CAD/CAM-generated posterior crowns. Dent Mater 2006;22:29-36

[12]. Heintze SD, Cavalleri A, Forjanic M, Zellweger G, Rousson V. Wear of ceramic and antagonist--a systematic evaluation of influencing factors in vitro. Dent Mater 2008;24:433-49

[13]. Apel E, Deubener J, Bernard A, Höland M, Müller R, Kappert H, Rheinberger V, and W. Höland W. Phenomena and mechanisms of crack propagation in glass-ceramics. J Mech Behav Biomed Mater 2008;1:313-25

[14]. Nakamura T, Ohyama T, Imanishi A, Nakamura T, Ishigaki S. Fracture resistance of pressable glass-ceramic fixed partial dentures. J Oral Rehabil 2002;29:951-5

[15]. Al-Dohan HM, Yaman P, Dennison JB, Razzoog ME, Lang BR. Shear strength of core-veneer interface in bi-layered ceramics. The Journal of prosthetic dentistry 2004;91:349-55

[16]. Aboushelib MN, Kleverlaan CJ, Feilzer AJ. Microtensile bond strength of different components of core veneered all-ceramic restorations. Part 3: double veneer technique. J Prosthodont 2008;17:9-13

[17]. Webber B, McDonald A, Jonathon Knowles J. An in vitro study of the compressive load at fracture of Procera AllCeram crowns with varying thickness of veneer porcelain. J Prosthet Dent 2003;89:154-60

[18]. Pallis K, Griggs J, Woody RD, Guillen GE, Amp W Miller AW. Fracture resistance of three all-ceramic restorative systems for posterior applications. J Prosthet Dent 2004;91:561-9

[19]. Blatz MB, Oppes S, Chiche G, Holst S, Sadan A. Influence of cementation technique on fracture strength and leakage of alumina all-ceramic crowns after cyclic loading. Quintessence Int 2008;39:23-32

[20]. AL-Makramani BM, Razak AA, Abu-Hassan MI. Evaluation of load at fracture of Procera AllCeram copings using different luting cements. J Prosthodont 2008;17:120-4

[21]. Miskinis SB, Snyder M, Sierraalta M, Billy E, Razzoog ME. Effect of varying coping thickness on early load-to-fracture strength of Procera AllCeram copings cemented with 2 resin-modified glass-ionomer cements. Quintessence Int 2008;39:501-5

[22]. Chaiyabutr Y, McGowan S, Phillips KM, Kois JC, Giordano RA. The effect of hydrofluoric acid surface treatment and bond strength of a zirconia veneering ceramic. J Prosthet Dent 2008;100:194-202

[23]. Nikzad S, Azari A, Dehgan S. Ceramic (Feldspathic \& IPS Empress II) vs. laboratory composite (Gradia) veneers; a comparison between their shear bond strength to enamel; an in vitro study. J Oral Rehabil 2010;37:569-74

[24]. Chun YH, Raffelt C, Pfeiffer H, Bizhang M, Saul G, Blunck U, Roulet JF. Restoring strength of incisors with veneers and full ceramic crowns. J Adhes Dent 2010;12:45-54 
Table I.

\begin{tabular}{|l|l|l|l|}
\hline \multicolumn{3}{|c|}{ Crowns } & \\
\hline MC & & $\%$ & $\%$ cumulative \\
\hline & First year & 1.33 & 1.33 \\
\hline & Second year & 3.63 & 4.95 \\
\hline & Third year & 3.16 & 8.11 \\
\hline & Fourth year & 0.58 & 8.69 \\
\hline
\end{tabular}

Table II.

\begin{tabular}{|l|l|l|l|}
\hline \multicolumn{2}{|l|}{ Crowns } & $\%$ & $\%$ cumulative \\
\hline & First year & 0.50 & 0.50 \\
\hline \begin{tabular}{l|l|} 
Second year \\
Third year
\end{tabular} & 0.00 & 0.50 \\
\hline Fourth year & 1.13 & 1.63 \\
\hline
\end{tabular}

Table III.

\begin{tabular}{|l|l|l|l|}
\hline \multicolumn{2}{|c|}{ Crowns } & $\%$ & $\%$ cumulative \\
\hline F & First year & 0.17 & 0.17 \\
\hline & Second year & 0.52 & 0.68 \\
\hline & Third year & 0.68 & 1.53 \\
\hline & Fourth year & 0.58 & 2.79 \\
\hline
\end{tabular}

Table IV.

\begin{tabular}{|c|c|c|c|}
\hline & Veneers & & \\
\hline \multirow[t]{5}{*}{$\mathrm{MC}$} & & $\%$ & $\%$ cumulative \\
\hline & First year & 0.60 & 0.60 \\
\hline & Second year & 2.60 & 3.20 \\
\hline & Third year & 0.00 & 3.20 \\
\hline & Fourth year & 0.00 & 3.20 \\
\hline
\end{tabular}

Table V.

\begin{tabular}{|l|l|l|l|}
\hline \multicolumn{2}{|l|}{ Veneers } & $\%$ & $\%$ cumulative \\
\hline & First year & 0.60 & 0.60 \\
\hline & Second year & 1.30 & 1.90 \\
\hline & Third year & 1.55 & 3.45 \\
\hline & Fourth year & 2.38 & 5.83 \\
\hline
\end{tabular}


Table VI

\begin{tabular}{|c|c|c|c|}
\hline \\
\hline & Veneers & & \\
\hline \multirow[t]{5}{*}{ VF } & & $\%$ & $\%$ cumulative \\
\hline & First year & 0.00 & 0.00 \\
\hline & Second year & 0.00 & 0.00 \\
\hline & Third year & 0.78 & 0.78 \\
\hline & Fourth year & 7.14 & 7.92 \\
\hline
\end{tabular}

Table VII.

\begin{tabular}{|c|c|c|c|}
\hline & Veneers & & \\
\hline \multirow[t]{5}{*}{$\mathrm{F}$} & & $\%$ & $\%$ cumulative \\
\hline & First year & 6.02 & 6.02 \\
\hline & Second year & 2.60 & 8.62 \\
\hline & Third year & 10.85 & 19.47 \\
\hline & Fourth year & 3.57 & 23.05 \\
\hline
\end{tabular}

Fig. 1. Graph showing probability of aluminium oxide crown and the aluminum oxide veneer survival to year 4

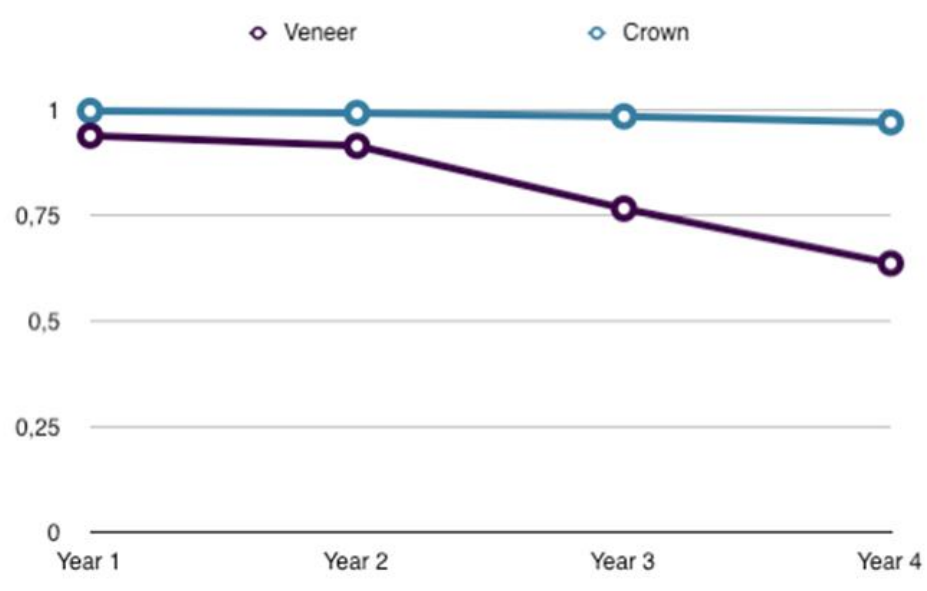

Fig. 2. Scanning electron microscope image (500 x magnification) of the alumina veneers.

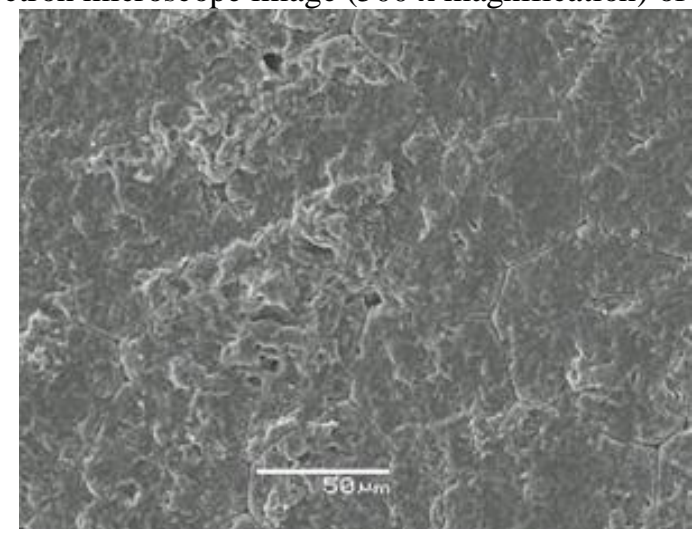


Fig. 3. Scanning electron microscope image (500 x magnification) of the feldspathic veneers.

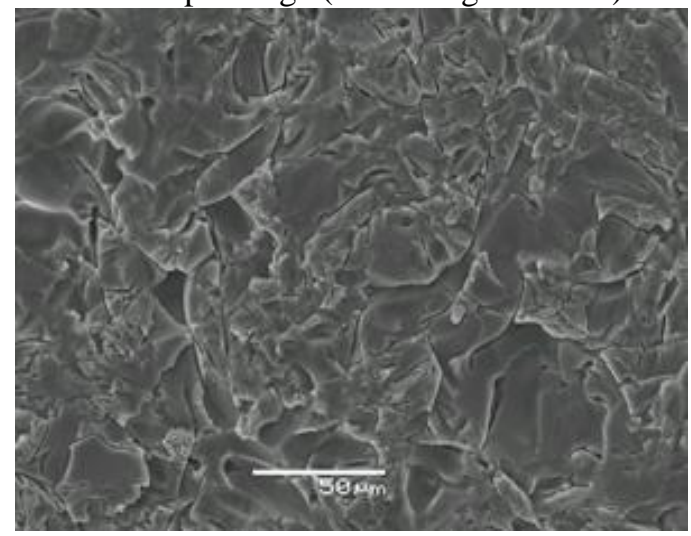

Fig. 4. Scanning electron microscope image (500 x magnification) of the alumina core.

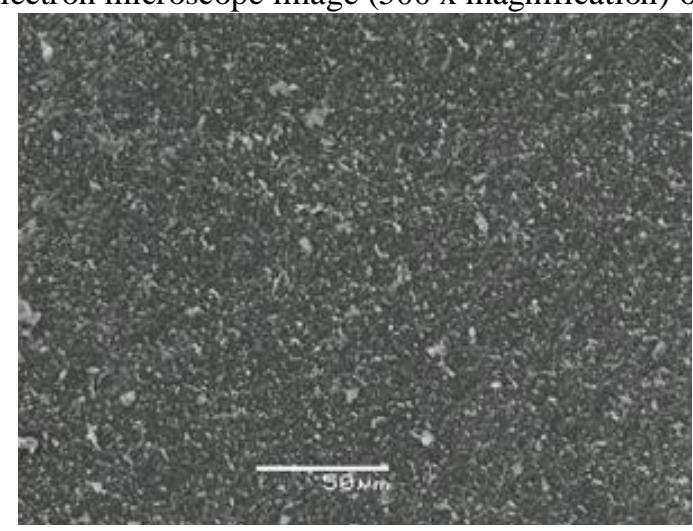

